\title{
PELATIHAN BLENDED LEARNING SEBAGAI ALTERNATIF PEMBELAJARAN SELAMA PANDEMI
}

\author{
Anggun Variasi Islami'1), M. Abdurrahman Sunni'²) \\ 1)Program Studi Teknik Komputer, Universitas Teknologi Mataram, Mataram, NTB, Indonesia \\ Corresponding author : Anggun Variasi Islami \\ E-mail : variasi.anggun@gmail.com \\ Diterima 30 Juli 2021, Direvisi 07 Agustus 2021, Disetujui 07 Agustus 2021 \\ ABSTRAK
}

\begin{abstract}
Bergesernya pola belajar pada masa pandemi ini menjadi inspirasi terlaksananya kegiatan Pengabdian Kepada Masyarakat ini. Dimulai dengan belajar penuh dari rumah hingga masuk sekolah secara bergantian. Mitra pada kegiatan ini adalah MTs NW Kilang Yang terletak di Kecamatan Montong Gading. Permasalahan utama yang dihadapi guru-guru adalah belum memahami bagaimana proses belajar secara daring baik secara full mauoun secara blended learning. Hal tersebut berdampak pada belajar hanya dilakukan secara tatap muka selebihnya diberikan PR untuk dikerjakan di rumah. Kegiatan ini bertujuan untuk mempersiapkan guru-guru MTs NW Kilang agar bisa melaksanakan belajar secara daring dimulai dengan blanded learning. Kegiatan ini dilaksanakan secara tatap muka langsung dengan metode seminar, praktik dan tanya jawab. Peserta dalam kegiatan ini terdiri dari 10 orang peserta yang berasal dari berbagai guru Mata pelajaran. Setelah kegiatan ini dilaksanakan, diharapkan peserta pelatihan mampu memahami konsep blended learning secara baik serta mampu menerapkankannya dikelas masing-masing. Pelaksanaan blended learning dengan google classroom dipilih karena google classroom sudah lebih familiar di kalangan peserta dibandingkan dengan yang lainnya. Untuk tahap pembelajaran penggunaan google classroom merupakan pilihan yang tepat. Ada beberapa tahapan yang dilakukan dalam kegiatan ini yaitu tahap persiapan dimana pelaksana kegiatan berdiskusi dengan pihak sekolah mengenai permasalahan yang dihadapi selama pandemi sehingga perlu dicarikan solusi yang tepat. Tahapan kedua adalah pelaksanaan kegiatan, dimana pelaksanaan kegiatan dan jenis kegiatan yang dilakukan pada tahapan ini tergantung dari hasil diskusi pada tahap persiapan.
\end{abstract}

Kata kunci: pembelajaran; blended learning

\begin{abstract}
The change in learning patterns during this pandemic has inspired the implementation of this Community Service activity. Starting with full learning from home to attending school alternately. The partner in this activity is MTs NW Kilang which is located in Montong Gading District. The main problem faced by teachers is that they do not understand how the online learning process is carried out either in full or in blended learning. This has an impact on learning only done face-to-face, the rest are given homework to do at home. This activity aims to prepare MTs NW Kilang teachers to be able to carry out online learning starting with blended learning. This activity is carried out face-to-face with the method of seminars, practice and question and answer. Participants in this activity consisted of 10 participants from various subject teachers. After this activity is carried out, it is hoped that the training participants will be able to understand the concept of blended learning well and be able to apply it in their respective classes. The implementation of blended learning with Google Classroom was chosen because Google Classroom was more familiar among the participants than the others. For the learning stage, the use of Google Classroom is the right choice. There are several stages carried out in this activity, namely the preparation stage where the implementer of the activity discusses with the school about the problems faced during the pandemic so that it is necessary to find the right solution. The second stage is the implementation of activities, where the implementation of activities and the types of activities carried out at this stage depend on the results of discussions at the preparation stage.
\end{abstract}

Keywords: learning; blended learning

\section{PENDAHULUAN}

Pembelajaran pada masa pandemi Covid-19 telah banyak bergeser. Mulai dengan pembelajaran dari rumah secara penuh kemudian masuk sekolah secara bergantian agar dalam satu kelas siswa bisa jaga jarak. Bagi sekolah yang berada di perkotaan itu menjadi tidak terlalu berdampak, karena 
fasilitas untuk siswa baik dalam belajar jarak jauh lebih memadai. Guru dan orang tua siswa bisa berkoordinasi untuk melakukan pembelajaran secara daring karena hampir semua orang tua siswa di daerah perkotaan HP bahkan Laptop. Akan tetapi hal tersebut berbeda untuk daerah pedesaan, meskipun sekarang fasilitas HP juga di miliki oleh siswa akan tetapi pembelajaran secara daring belum terlaksana.

Pembelajaran di daerah pedesaan khususnya MTs NW Kilang masih tetap di lakukan secara Luring dengan cara membagi jam belajar. Jam belajar menjadi lebih pendek karena dikhawatirkan berada di satu ruangan secara bersama terlalu lama. Hal tersebut berdampak pada materi pembelajaran yang tidak tuntas. Berangkat dari alasan tersebut maka di perlukan tambahan pembelajaran secara daring. Pembelajaran yang dilakukan dengan kombinasi daring dan luring tersebut dinamakan Blended learning. Seperti yang dikatakan oleh Wardani dkk (2018), Blended learning dikembangkan karena kelemahankelemahan yang muncul pada pembelajaran tatap muka dan e-learning.

Regulasi pembelajaran e-learning baik secara full daring maupun blended learning saat ini sedang digodok oleh pemerintah. Selain karena alasan pandemi, peningkatan kualitas dan pemerataan layanan pendidikan juga menjadi alasan yang penting untuk melakukan pembelajaran secara blended learning. Guru dan siswa belajar untuk menggunakan fasilitas HP, Laptop dan internet secara lebih bijak untuk kebutuhan pendidikan. Sehingga mutu pendidikan baik di perkotaan maupun di pedesaan menjadi lebih merata.

Dengan adanya blended learning, proses belajar mengajar tidak hanya terjadi di sekolah akan tetapi bisa dari rumah. Materi yang belum di pahami pada saat pertemuan daring dapat di bahas lebih mendalam pada saat pembelajaran luring begitu pula pembelajaran daring mengajarkan siswa untuk bisa lebih aktif membaca sendiri materi yang ada sehingga pembelajaran tidak hanya berpusat pada guru. Pembelajaran secara blended learning juga memberikan angin segar kepada siswa yang terlalu biasa belajar secara luring yang hanya mendengarkan guru menjelaskan. Melalui blended learning, peserta didik tidak hanya mendengarkan uraian materi dari pendidik secara luring saja tetapi juga aktif mengamati, melakukan, mendemonstrasikan, dan sebagainya secara daring. Materi bahan ajar dapat divirtualisasikan dalam berbagai format sehingga lebih menarik dan lebih dinamis sehingga mampu memotivasi peserta didik untuk lebih jauh dalam proses pembelajaran. Blended learning juga dapat mengakomodasi perkembangan teknologi yang luas tanpa harus mneninggalkan tatap muka (Wardani dkk. 2018). Melihat pentingnya strategi belajar blended learning pada masa ini beberapa ahli berpendapat bahwa blended learning menjadi pilihan tepat dalam melaksanakna proses belajar mengajar

Proses pembelajaran blended learning tentu tidak akan berjalan dengan baik jika guru sebagai fasilitator tidak memahami konsep dan metode pembalajaran tersebut. Seperti halnya guru di Mts NW Kilang, pembelajaran hanya dilakukan secara luring, belum ada arahan untuk melakukan pembelajaran secara daring. Belum memahami alur untuk melakukan pembelajaran secara blended learning menjadi alasan utamanya. Meskipun pembelajaran secara blended learning sudah sering di gaungkan akan tetapi secara pelaksanaan sangat asing bagi guru MTs NW Kilang. Seperti dikatakan, tak kenal maka tak sayang maka perlu di perkenalkan kepada guru-guru Mts. NW Kilang proses blended learning agar dapat menerapkan di kelas masing-masing.

\section{METODE}

Pengabdian kepada Masyarakat ini dilaksanakan dengan menggunakan tatap muka langsung dengan metode seminar, praktek dan Tanya jawab. Pelatihan dilakukan selama 1 hari dilakukan di Mts NW Kilang dengan menerapkan Prokes kesehatan. Peserta menggunakan laptop dan atau smartphone sebagai media sedangkan untuk internet disediakan di sekolah setempat. Praktik secara langsung dilakukan untuk mengetahui kendala yang dihadapi oleh tiap peserta sehingga dapat di cari solusi dengan segera.

Pada dasarnya sangat banyak aplikasi penunjang untuk pembelajaran secara blended learning akan tetapi pada saat pelaksanaan pengabdian pada masyarakat ini Aplikasi penunjang yang digunakan adalah Google Classsroom. Hal tersebut untuk memudahkan guru karena aplikasinya angat mudah diakses.

Subjek dampingan pada kegiatan ini adalah MTs. NW Kilang yang dilaksanakan pada bulan Juni 2021. Kegiatan ini dilaksanakan sebagai solusi yang di tawarkan pelaksana kegiatan dari berbagai keluhan guru dan murid yang merasa jam belajar menjadi sangat singkat. Madrasah menyetujuinya karena sangat bermanfaat untuk keberlangsungan proses belajar mengjar guru dan murid pada masa pandemi.

Secara teknik kegiatan ini terdiri dari tiga tahapahan yaitu tahap Persiapan dan Pelaksanaan. Sedangkan Rincian kegiatan 
pelaksanaan Pengabdian Pada Masyarakat ini dilakukan dengan tahapan

a. Perkenalan pembicara seminar

b. Pengenalan beberapa aplikasi blended learning yang dapat di gunakan

c. Pendalaman materi mengenai blended learning

d. Praktik langsung penggunaan blended learning (google classroom)

e. Melakukan Tanya jawab

Perangkat pendukung kegiatan Pengabdian Kepada Masyarakat

a. Laptop/ smartphone

b. Wifi

\section{HASIL DAN PEMBAHASAN}

\section{Pengertian blended learning}

Blended learning adalah strategi mengajar yang bertujuan untuk mencapai tujuan pembelajaran berbasis tatap muka dengan pembelajaran berbasis teknologi dan informasi yang dilakukan secara online (I ketut Widiare, 2018). Selanjutnya Straker., (2012), menyatakan bahwa blended learning merupakan pembelajaran yang dilakukan di pendidikan formal yang memungkinkan siswa untuk belajar sebagian melalui konten dan petunjuk disampaikan secara online. Sehingga dapat dikatakan bahwa blended learning merupakan perpaduan antara belajar secara tatap muka dengan belajar secara daring melalui penggunaan fasilitas internet. Populernya pembelajaran klasik metode ceramah tatap muka di Indonesia mengakibatkan siswa memiliki ketergantungan kepada guru sebagai fasilitator sehingga kemampuan berfikir kritis dan kreatif siswa kurang terasah. Hal tersebut sesuai dengan pendapat Ratna sari, Anissa., (2013), yang menyatakan bahwa dampak lain dari pembelajaran metode klasikal akan menyebabkan kemampuan critical thingking kurang terasah karena tidak terbiasa untuk berfikir sendiri di luar konteks yang disampaikan.

Kelebihan dari blended learning

a. peserta didik leluasa untuk mempelajari materi pelajaran secara mandiri dengan memanfaatkan materi yang tersedia secara online

b. peserta didik dapat berkomunikasi/ berdiskusi dengan pengajar atau peserta didik lain yang tidak harus dilakukan saat di kelas (tatap muka)

c. kegiatan pembelajaran yang dilakukan peserta didik di luar jam tatap muka dapat dikelola dan dikontrol dengan baik oleh pengajar d. pengajar dapat menambahkan materipengayaan melalui fasilitas internet

e. pengajar dapat meminta peserta didik membaca materi atau mengerjakan tes yang dilakukan sebelum pembelajaran

f. pengajar dapat menyelenggarakan kuis, memberikan balikan, dan memanfaatkan hasil tes dengan efektif.

g. peserta didik dapat saling berbagi file dengan peserta didik lainnya.

Tabel 1. kekuatan dan kelemahan pembelajaran online dan tradisional

\begin{tabular}{|c|c|c|c|}
\hline & & nline & Tatap muka \\
\hline \multirow[t]{2}{*}{ kekuatan } & a. & $\begin{array}{l}\text { fleksibelitas, } \\
\text { partisipasi } \\
\text { siswa terjadi } \\
\text { dalam waktu } \\
\text { dan tempat } \\
\text { yang nyaman } \\
\text { bagi siswa } \\
\text { Partisipasi, } \\
\text { semiswa } \\
\text { berpartisipasi } \\
\text { dikarenakan } \\
\text { ua urangnya } \\
\text { hambatan } \\
\text { waktu dan } \\
\text { tempat } \\
\text { Kedalam } \\
\text { refleksi, siswa } \\
\text { memiliki } \\
\text { waktu yang } \\
\text { lebih untuk } \\
\text { mempertimba } \\
\text { ngkan respon } \\
\text { mereka }\end{array}$ & 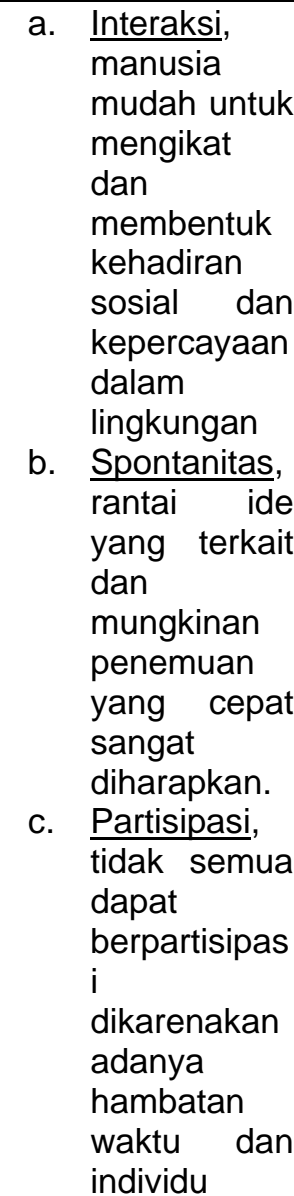 \\
\hline & & online & Tatap muka \\
\hline $\begin{array}{l}\text { kelemah } \\
\text { an }\end{array}$ & b. & $\begin{array}{l}\text { Spontanitas, } \\
\text { rantai ide } \\
\text { yang terkait } \\
\text { dan } \\
\text { kemungkinan } \\
\text { penemuan } \\
\text { yang cepat } \\
\text { tidak dapat } \\
\text { diharapkan. } \\
\text { Penundaan, } \\
\text { mahasiswa } \\
\text { mungkin } \\
\text { menyerahata } \\
\text { u menunda }\end{array}$ & $\begin{array}{l}\text { a. Fleksibelitas, } \\
\text { karena alasan } \\
\text { keterbatasan } \\
\text { waktu, } \\
\text { pengajar } \\
\text { mungkin tidak } \\
\text { dapat meraih } \\
\text { diskusi yang } \\
\text { mendalam } \\
\text { sesuai } \\
\text { keinginan }\end{array}$ \\
\hline
\end{tabular}


untuk

berpartisipasi

secara

langsung

\section{Persiapan}

Tahap persiapan ini merupakan tahapan awal sebelum menentukan jenis kegiatan. Pelaksana melakukan survey ke Madrasah untuk mengetahui keluhan-keluhan dari pihak madrasah baik itu guru maupun dari murid. Kegiatan ini di laksanakan pada bulan April 2021 dengan temuan bahwa kurangnya jam pembelajaran sejak terjadinya pandemi.

Dari hasil diskusi dengan beberapa guru mengenai solusi menggunakan blended learning kemudian disampaikan kepada Kepala Madrasah untuk di tindak lanjuti. Banyak kekhawatiran di sampaikan oleh Kepala Madrasah terkait dengan jika pembelajaran daring di laksanakan akan tetapi Kepala Madrasah mendukung guru-guru untuk belajar menggunakan blended learning. Jika guru-guru sudah siap untuk melaksanakan kegiatan belajar mengajar dengan blended learning maka setidaknya sekolah sudah siap jika suatu saat diharuskan untuk menggukan metode tersebut.

Pada tahap ini pelaksana kegiatan dan Kepala sekolah sepakat untuk fasilitas penunjang seperti laptop atau Smartphon dan wifi akan disediakan sendiri oleh peserta seminar. Tempat pelaksanaan kegiatan berlangsung hanya di Sekolah Pada saat siswa pulang sekolah.

\section{Pelaksanaan}

Tahap pelaksanaan ini terlaksana berdasarkan kesepakatan antara pelaksana kegiataan Pengabdian Kepada Masyarakat dengan subjek dampingan. Kegiatan dilakukan pada 25 Juni 2021. Kegiatan di mulai dengan pengenalan Para Pembicara kemudian dilanjutkan dengan Brainstorming tentang blended learning dan pembelajaran daring. Hampir semua guru sering mendengar kata pembelajaran daring akan tetapi belum pernah melakukan secara langsung. Bahkan sebagian guru ada yang belum mengetahu jenis-jenis aplikasi apa saja yang bisa digunakan untuk melaksanakan pembelajaran secara daring.

Guru-guru memiliki kekhawatiran yang besar dalam melaksanakan pembelajaran secara daring, selain karena pengetahuan tentang proses pembelajaran yang belum di kuasai juga mengenai ekstra biaya yang harus di keluarkan para murid untuk membeli kuota. Terlepas dari semua kendala tersebut yang terpenting guru harus memiliki kesiapan jika suatu saat diharuskan melakukan pembelajaran secara daring sehingga perlu untuk melakukan kegiatan ini.

Guru diberikan materi mengenai bagaimana mengkombinasikan pembelajaran tatap muka dengan pembelajaran daring. Pembelajaran daring yang di latih adalah google classroom karena kata google sendiri sudah sangat familier dan juga google classroom mudah dipahami.

Pelatihan dengan google classroom dimulai dengan kelebihan dan kekurangan aplikasinya dan apa saja fitur yang bisa di manfaatkan. Peserta diajarkan langsung bagaimana membuat akun sebagai pengajar yang dilanjutkan dengan bagaimana menggunakan fitur-fitur yang ada. Peserta di ajarkan bagaimana menggunggah materi, membuat tautan, memberi tugas, mengoreksi tugas, membuat pengumuman, merekap nilai di laman google classroom.

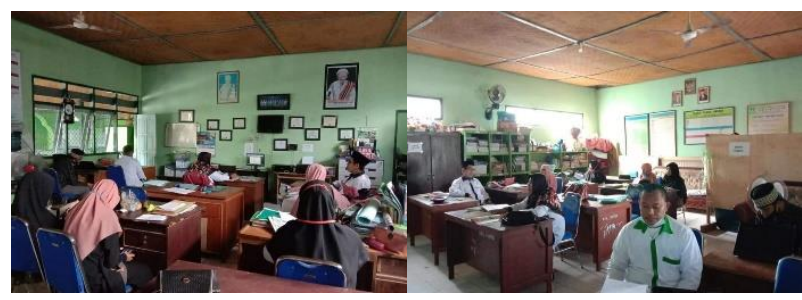

Gambar 1. Proses Pelaksanaan Pelatihan Blended Learning

Setelah materi diberikan, perserta melakukan praktek secara langsung pada laptop atau smartphone sehingga lebih mengetahui dimana letak kesulitannya.

Sebagian besar peserta tidak kesulitan yang berarti dalam membuat akun karena sudah sangat akrab dengan dunia digital. Penggunaan laptop/smartphone dan internet sudah menjadi keseharian baik di rumah maupun di sekolah. Akan tetapi ada beberapa guru senior yang memang baru dalam penggunaan digital sehingga perlu pendampingan lebih.

Peserta hanya perlu diberikan motivasi untuk lebih percaya diri mencoba hal baru. Peserta kadang merasa khawatir salah klik fiturfitur yang ada di google classroom sehingga jika tidak yakin maka akan bertanya dan tidak melakukan apapun.

\section{SIMPULAN DAN SARAN Simpulan}

Antusiasme peserta pelatihan untuk mempelajari blended learning sangat besar. Hampir semua dapat memahami dasar-dasar pembelajaran blended learning sehingga pelatihan dapat berlangsung tanpa kendala yang berarti. Hal tersebut dapat dilihat dari 
hampir semua peserta telah mampu membuat akun sendiri serta memasukkan materi ke google classroom sehingga dapat menjadi modal awal pelaksanaan blended learning kelak di kelas masing-masing.

\section{Saran}

Selain memanfaatkan situs belajar google classroom, para pengajar juga dapat menggunakan situl belajar yang lain seperti Zenius, Moodle, Canvas, Schoology, Blackboard Learn, D2L Brightspace, Edmodo, Quizlet

\section{Ucapan terima Kasih}

Ucapan terima kasih kepada yayasan Darma Bakti atas support dananya. Serta pada Kepala Sekolah untuk fasilitas penunjang lainnya.

\section{DAFTAR RUJUKAN}

Graham, C. R. (2006). Blended Learning Systems. The Handbook of Blended Learning, 3-21

Husamah. (2014). PEMBELAJARAN BAURAN (BLENDED LEARNING) Terampil Memadukan Keunggulan Pembelajaran Face-To-Face, Elearning Offline-Online, dan Mobile Learning. Jakarta: Prestasi Pustaka

I Ketut Widiare. (2018). Blanded Learning Sebagai Alternatif Pembelajaran Era Digital. Purwadita: Jurnal Agama dan Budaya. 2 (2)

Irawan, E. (2019). Digitalisasi Madrasah di Era Revolusi Industri 4.0: Refleksi Kegiatan Pengabdian Kepada Masyarakat di Kabupaten Ponorogo. E-Dimas: Jurnal Pengabdian Kepada Masyarakat, 10(2), 160-168.

Wardana, DN dkk. (2018). Daya Tarik Pembelajaran Di Era 21 Dengan Blended Learning. Jurnal Kajian Teknologi Pendidikan. 1 (1)

Ratna Sari, Anisa. (2013). Strategi Blended Learning Untuk Peningkatan Kemandirian Belajar Dan kemampuan Critical Thingking Mahasiswa Di era . XI. Jurnal Pendidikan Akuntansi Indonesia. 11 (2).

Staker,H., Horn, M.B. (2012). Classifying K-12 Blended Learning. Innosight Institute 